\title{
A Comparison of Leadership Theories in an Organizational Environment
}

\author{
Robert Cote $^{1}$ \\ ${ }^{1}$ Program Director - Management, Lindenwood University, St. Charles, USA \\ Correspondence: Dr. Robert Cote, Program Director - Management, Lindenwood University, St. Charles, Missouri \\ 63301, USA.
}

Received: May 24, 2017

Accepted: June 12, 2017

Online Published: July 9, 2017

doi:10.5430/ijba.v8n5p28

URL: https://doi.org/10.5430/ijba.v8n5p28

\begin{abstract}
This analysis will review three leadership theories focusing on how leader's influence and motivate employees to accomplish tasks and goal achievement in an organizational environment. The three theories chosen are: (1) Situational Leadership Theory, (2) Path-Goal Leadership Theory, and (3) Leader-Member (LMX) Theory. In each leadership theory, background information, development and effectiveness, and strengths and weaknesses will be analyzed. Also, each leadership theory will be compared and contrasted according to similarities and differences. After each of these theories of leadership is reviewed, the last section will discuss Transformational Leadership, which has become an emerging leadership theory because it inspires, motivates, and energizes employees.
\end{abstract}

Keywords: leadership, leadership theories, situational leadership, path-goal, leader-member, transformational, emerging leadership, organizational, employees

\section{Introduction}

Leadership has been researched over the last century with many classifications developed to define leadership. According to Bennis (1982), "there are more than 350 definitions of leadership" (p. 44). The many definitions of leadership have focused on group process leadership, skills approach, behavior approach, trait approach, situational approach, and many more. To simplify the definition of leadership, it is a process that involves influencing an individual or a group in efforts toward goal achievement (Hersey et al., 1979). Based on the definition, the following components are central, which are: (1) Leadership is a process that is a transactional event that occurs between leader and followers, (2) Leadership occurs in group situations, (3) Leadership involves influencing followers, and (4) Leadership includes goal attainment (Northouse, 2007).

In the article, "The Artform of Leadership", Bennis (1982) conducted a study on 90 CEO's to learn which competencies were shared and incorporated in their roles to successfully translate intention into reality in organizations, while maintaining consistency. Based on his findings, the effective CEO's were able to create a clear vision, influence followers by communicating the vision to gain support, maintain organizational direction through persistence and consistency, and the capacity to empower followers to tap and harness the energy to achieve desired results or outcomes (Bennis, 1982).

Based on the definition of leadership, this paper will analyze three leadership theories focusing on the process, by which a leader influences and motivates followers to achieve goal accomplishment. The following three leadership theories have been chosen, which are: (1) Situational Leadership focusing on leaders adapting their behavior style to meet needs of employees in different situations to achieve goals (tasks), (2) Path-Goal Theory focusing on the leader's style to enhance follower's performance and increase satisfaction by motivating them to accomplish designated goals., and (3) Leader-Member (LMX) Theory focusing on the exchanges (low/high) between the leader and the follower(s) in a dyadic relationship to reach goal achievement (Northouse, 2007).

In the next sections, the leadership theory's will be discussed covering the following topics, which are background information on the theories origin, information on development and relative effectiveness, and discussion on strengths and weaknesses.

\section{Situational Leadership}

\subsection{Background Information}

The 3-D Management Style Theory made a significant contribution to the field of leadership and the foundation for 
developing the Life Cycle Theory of Leadership known as Situational Leadership I (Blanchard et al., 1993). Based on Reddin's research, he examined the classification of the behavior of managers in two underlying variables, which are task orientation and relationship orientation. Task orientation is defined as the extent a leader will direct their own and subordinates efforts towards goal attainment and relationship orientation is defined as an established relationship between a leader and subordinate to establish trust, respect and consideration for ideas and feelings.

Because of previous studies classifying these variables, there was confusion between non-normative (latent style) and normative issues on whether one style was more or less effective than the other. As a result of this issue, he developed a 3-D Management Style Model consisting of twelve types. According to Reddin (1967), he explains "if any style may be less-effective or more-effective, depending on the circumstances, than each non-normative or latent style will have two behavioral counterparts, one less-effective an the other more-effective (p. 13). Based on these styles, typology will consist of 12 sections, which are four less-effective types, four latent types, and four more-effective types. The effectiveness between less-effective and more-effective results will be based on the manager's style that fits the situation, task and relationship orientation (Reddin, 1967; Blanchard et al., 1993).

\subsection{Development and Relative Effectiveness}

In the 1972 edition of Management of Organizational Behavior, Hersey and Blanchard began to describe their approach to leadership by using the term "situational leadership" instead of the original "life-cycle theory of leadership" (Blanchard et al., 1993). Based on Reddin's earlier work, they tried to emphasize behavior dimensions are "task behavior" and "relationship behavior" rather than attitude dimensions of "task orientation" and "relationship orientation" (Blanchard et al., 1993; Hersey \& Blanchard, 1996).

In Situational Leadership I (SLI), it was based on the relationship between the two dimensions (task and behavior) and maturity. It is divided into four quadrants based on relationship and task, which are quadrant I (high task/low relationship), quadrant II (high task/high relationship), quadrant III (low task/high relationship), and quadrant IV (low task/low relationship). The model is an attempt for leaders to find some understanding between the effective leader's style and the follower's maturity. The model is focused on the interaction between the leaders and followers. They believe followers can individually accept or reject a leader, while groups can determine a leader's personal power. As follower's level of maturity increases, the leader's behavior becomes less structured requiring less socio-emotional support. For example, a structure task behavior would be appropriate for an immature follower with a leader's behavior moving from high task/low relationship to high task/high relationship behavior. As the follower matures, the leader can move from a high task/high relationship to a low task/low relationship. This style suggests a basic style for different levels of maturity to meet certain goal accomplishment (Blanchard et al., 1993; Hersey \& Blanchard, 1996).

Based on the SLI model, in 1985, the revised Situational Leadership II (SLII) model was published in a series of articles written by Blanchard. In the SLII model, the four quadrants were divided by leadership styles and development level of subordinates was added. Also, changes were done to accommodate behaviors for helping others successful completes a task. As a result, the old dimensions were changed from "task behavior" and "relationship behavior" to "directive behavior (low/high)" and "supportive behavior (low/high)." As leadership begins to evolve toward followers, the newer model focused on leaders changing the level of support or direction to help followers meet their changing needs (Blanchard et al., 1993; Hersey \& Blanchard, 1996).

For leadership styles in SLII, the four quadrants were labeled to conceptualize the different styles of leadership and situational leadership, which are: (1) style 1: directing - high directive/low-supportive (2) style 2: coaching high-directive/high-supportive, (3) style 3: supporting - high-supportive/low-directive, and (4) style 4: delegating low-supportive/low-directive (Blanchard et al., 1993; Hersey \& Blanchard, 1996).

For the development level of followers, according to Blanchard et al. (1993), "refers to the extent to which a person has mastered he skills necessary for the task at hand and has developed a positive attitude towards the task (p. 27). The development levels are based on level of competency, which are: (1) development level 1 - new to task with low competence/high commitment, (2) development level 2 - developed some competence may need more supportive behavior from leader, and (3) development level 3 - has moderate to high competence may need high supportive/low directive behavior, and (4) development level 4 - highest competence with high commitment/high competence. To determine which style is appropriate, it depends on the degree of difficulty of the task and where is the follower in the development level (Blanchard et al., 1993; Hersey \& Blanchard, 1996; Blanchard, 2004; Blanchard, 2008).

\subsection{Strengths and Weaknesses}

Based on SLII model, there are several positive strengths, which are: (1) the implementation of the grid for level of 
development has enabled leaders to better determine their level of performance of staff, (2) by labeling SLI quadrants with leadership styles, this revision has enabled leaders to effectively influence staff based on style and behavior, (3) SLII stresses leadership flexibility allowing leaders to adapt their style to be responsive to their staff needs, and (4) organizational bottom line improves as the level of development and performance by staff increases (Blanchard, 2004; Graeff, 1983).

Although the model have many positive strengths, SLII has several weaknesses, which are: (1) lack of published research on SLII has limited information to support assumptions and propositions on the theory, (2) additional research needed for the development level to understand the correlation between competence and commitment focused on task accomplishment, (3) publication of a standard scores from a common instrument (LBAII), (4) match studies that examine development level on a specific goal or task, and (5) demographic studies don't adequately explain how the characteristics influence the leader (Blanchard et al., 1983; Boatwright \& Vecchio, 2002; Graeff, 1983; Graeff, 1997).

In the next section, Path-Goal Theory will be discussed covering the following topics, background information on the theories origin, information on development and relative effectiveness, and discussion on strengths (positives) and weaknesses (criticisms).

\section{Path-Goal Theory}

\subsection{Background Information}

Path-Goal Theory was inspired by work done by Martin Evans (1970) and influenced by another motivational Theory developed by Vroom called Expectancy Theory (Evans, 1970; House \& Mitchell, 1974). In 1970, Evans did work on "The Effects of Supervisory Behavior on the Path-Goal Relationship" to explain how a leader's behavior will impact an individual's path-goal instrumentalities. According to Evans (1970), the definition of path-goal instrumentality as "the individual's perception of how his action or behavior (path) may be related to the individual's idiosyncratic outcomes (goals), path-goal instrumentality is the extent to which the path is seen in helping or hindering the individual in attaining his goals" (p. 279). Also, predictions can be made based on the motivation for the individual to engage in a specific behavior based on the goal importance and perception of a behavior or action (path) may relate to the individual's outcome (goal). His work helped to explain the relationship between leadership behavior and the follower perceptions based on the degree of which following a particular behavior (path) will lead to a particular outcome (goal).

For a brief explanation of how Expectancy Theory influenced Path-Goal Theory is based on an individual believing that an increased effort will result in better job performance, while better job performance will result in rewards, and the value of the rewards will be motivating to an individual. According to House \& Mitchell (1970), attitudes and behavior can be predicted from: "(1) the degree to which the job, or behavior, is seen as leading to various outcomes (expectancy) and (2) the evaluation of these outcomes (valences)" (p.81). Based on this theory, it provides a basis of how leader's behavior influences motivation to achieve goal accomplishment (Evans, 1970; House \& Mitchell, 1974; House, 1996).

\subsection{Development \& Effectiveness}

In 1971, Path-Goal Theory was developed by Robert House, revised in 1974 by House \& Mitchell, and revised in 1996 by House (House, 1970; House \& Mitchell, 1974; House, 1996). In the initial version of Path-Goal Theory, House (1971) asserts that the function of the leader was through motivational functions, which "consists of increasing personal payoffs to subordinates for work-goal attainment and making the path to these payoffs easier to travel by clarifying it, reducing roadblocks and pitfalls, and increasing the opportunities for personal satisfaction en route" (p. 324).

As Path-Goal Theory was revised in 1974 by House and Mitchell; changes were noted to compare to the initial version of the theory. In 1974, House \& Mitchell included two general propositions to the theory, which are: (1) leader behavior is seen by individual as acceptable or satisfactory and the leader behavior is an immediate or future source of satisfaction, and (2) leaders behavior will motivate the individual to the extent that such behavior will satisfy the individuals contingent needs on performance and such behavior which accommodates the individuals environment to support and reward for effective performance. These propositions provide a basis for leader's strategic functions to help motivate individuals to perform their job, acceptance of the leader, and satisfaction with the job (House \& Mitchell, 1974; House, 1996).

Also, two classes of situational variables were postulated as contingency factors that can moderate the relationship between other variables, such as individual's satisfaction and leader behavior. The two contingency variables are: (1) 
individuals must cope with environmental pressures and characteristics to accomplish meeting tasks, and (2) individuals personal characteristics. Based on the propositions and contingency factors, would help explain the difficulty in the task completion may change the relationship between the leader's behavior and job satisfaction of the individual (House, 1971; House \& Mitchell; 1974).

In the initial version, House (1971) classified two types of leader's behavior, which are: (1) behavior directed toward the satisfaction of individual's needs, and (2) path-goal clarifying behavior. Base on these descriptions, they were not well defined operationally as part of the theory. In 1974, House \& Mitchell expanded the two types to four well defined behaviors, which are: (1) directive leadership is focused on giving psychological support to individuals by providing instructions on tasks, what is expected of them, how it is done, guidelines, and timeline, (2) supportive leadership is focused on leadership that consists of being friendly and approachable with a behavior directed towards satisfying the needs of individuals, (3) participative leadership is focused on a directive leadership behavior to encourage and influence individuals to participate in decision making, provide suggestions, and share ideas that will be integrated in the organization, and (4) achievement-oriented leadership is focused on a directive behavior who challenges individuals in setting performance goals, improvements, performance excellence to achieve high standards and increased confidence (House \& Mitchell, 1974; House, 1996).

Examples of how leadership behavior can be used with individuals in various task characteristics, which are: (a) directive behavior for individuals that are dogmatic and authoritarian due to ambiguous tasks, it would provide guidance and psychological structure for individuals, (b) supportive behavior for an individual completing a job that is unsatisfying or frustrating, it would provide positive effect on individual satisfaction, (c) participative behavior would also benefit individuals in a frustrating or ambiguous task, by providing participative support would give the individual clarity and path for meeting goals, and (d) achievement-oriented behavior for individuals in repetitive tasks, by challenging the individual to achieve high standards.

In 1996, House reformulated his initial theory to extend the previous work to include eight classes of leadership behaviors, which are: (1) work facilitation focused on leaders behavior that consists of scheduling, planning, and organizing work with individuals, (2) group-oriented decision process focused on leader behavior in coordinating group decisions based on the number of behaviors by unit leaders in the group, (3) representation and networking is focused on leader behavior presenting the group in a favorable manner to acquire the necessary resources to complete tasks, (4) value based leader behavior is focused on leader behavior that articulates the vision, display passion for the vision, demonstrate self-confidence, taking extraordinary personal and organizational risks, communicate high expectations, instill values, and positive evaluation of individuals (House, 1996).

Path-Goal Theory has gone through 25 years of evolution since its original publication in 1971. In theory, it provides leaders different leadership behaviors based on a set of assumptions that enables them to interact with individuals based on personal characteristics and environmental characteristics by influencing them to be motivated and satisfied with their job. In practice in today's work environment, it provides leaders direction on how to help individuals accomplish their task in a fashion that is satisfactory to them and the leader. The Path-Goal Theory suggests that leaders choose a leadership behavior that correlates to the work being done and best fits their needs of the individual. As an effective leader, they attend to the needs of subordinates, set goals, determine path (outcome), and help provide support when obstacles arise in reaching goal accomplishment (House \& Mitchell, 1974).

\subsection{Strengths and Weaknesses}

In Path-Goal Theory, there are several positive strengths, which are: (1) provided the groundwork for understanding situations where a leader's behavior will motivate an individual's performance and job satisfaction in four distinct leadership styles (Jermier, 1996), (2) path-goal theory is unique in motivating individuals based on the integration of Vroom's Expectancy Theory (House, 1971; House \& Mitchell; 1974), and (3) provides a great model for helping individuals clarify goals, set goals through coaching and direction to achieve goals of productivity (House \& Mitchell, 1974).

Although the theory has several positive strengths, it also has several weaknesses, which are: (1) the theory is very complex as noted through the stages of evolution, (2) there has partial support based on the many empirical studies for validity, (3) results of studies haven't provided a true correlation between the assumptions and path-goal theory (Schriesheim \& Schriesheim, 1980; House \& Mitchell, 1974), (4) understanding the relationship between leader and individual on motivation according to the expectancy theory (House \& Mitchell, 1974), and (5) Path-Goal theory is based on leaders behaviors (directive, supportive, participative, and achieve-oriented) to motivate individuals (House, 1996). 


\section{Leader-Member (LMX) Theory}

\subsection{Background Information}

The Vertical Dyad Linkage (VDL) Theory is the foundation of the Leader-Member (LMX) Theory, which has progressed and been refined many times since the earlier studies of the VDL approach, more than 20 years of research have been conducted on traditional leadership styles. In 1973 and 1975, Dansereau et al investigated the possible advantages of the VDL approach. Based on this approach, the relationship between the leader and follower is distinct and is based on the nature of the "vertical exchange." In the initial process of organizing the roles of the members of the dyad, the vertical exchange to determine latitude between leader and member in negotiating job related matters. If the member is given the opportunity to work through job related matters (negotiated role responsibilities), they are considered the in-group, while the leader is attempting leadership technique. When a leader is using leadership technique, they are not relying on the employment contract while having more social exchanges with the member. Instead, the leader must influence the member through other methods, such as an interpersonal exchange that can establish a relationship between leader and member. On the other hand, if the leader doesn't allow very much negotiating on job related matters (defined roles), the member is considered the out-group, while the leader is using supervision technique. In supervision technique, the leader relies on the employment contract when making exchanges with the member. Based on this agreement, the member agrees to fulfill all obligations of his contract. According to Dansereau et al (1975), "the greater the latitude initially given to the member to negotiate job-related matters, the higher the probability that the superior is attempting leadership and the lower the probability that he is using supervision with his member" (p. 50). Based on this early work on VDL, Dansereau et al (1975) were able to conclude that a superior can establish a leadership relationship with a member in one dyad and establish another leadership relationship with a member of another dyad. As a result, the members in the in-group received more influence, attention, and information than the out-group. The members in the in-group tend to be more dependable, communicative, and involved than the out-group (Dansereau et al., 1975).

\subsection{Development and Effectiveness}

LMX Theory is based on the relationship between the leader and follower that evolves over time based on the level of exchanges (Graen \& Uhl-Bien, 1995). Based on the previous research on VDL theory, its limitations was due to vertical linkages that were formed between the leader and select few of their followers. Instead of building relationships with all of their followers, the leader established multiple vertical dyads with followers on an individual basis. As the leader developed these relationships with individual followers, they were either placed in the in-group (working relationship) or the out-group (limited or no working relationship).

In recent studies, the focus has been shifted away from the differences between the in-group and out-group classification to concentrate on the quality of exchanges (low/high) between the leader and member can be used for leadership making to achieve positive outcomes with leaders, members, and groups in the organization (Graen \& Uhl-Bien, 1991; Graen \& Uhl-Bien, 1995; Schriesheim et al., 2001). Northouse (2007) explains that "leadership making is a prescriptive approach to leadership that emphasizes that a leader should develop high-quality exchanges with all of her or his subordinates rather than just a few" (p.155). As a focus of leadership making, the leader attempts to build partnerships through dyads with all of their members in the work units (Graen \& Uhl-Bien, 1995).

According to the leadership making process, it is based on three components, which are: (1) characteristics of leader, (2) characteristics of follower, and (3) maturity of leadership relationship. This model supports the leadership influence based on the context of exchanges (low/high) within the relationship. The relationship building process between leaders and followers occurs in three phases, which are: (1) leaders and followers come together as strangers on a more formal basis with low-exchanges being purely contractual, (2) leaders and follower's progress from strangers to acquaintances through an increased level of social exchanges to establish relationship, and (3) increased high exchange of information between leaders and followers "matures" the relationship, progressively resulting in higher degrees of respect, mutual trust, and obligations within the relationship (Graen \& Uhl-Bien, 1991, Graen \& Uhl-Bien, 1995).

\subsection{Strengths and Weaknesses}

In LMX Theory, there are several positive strengths regarding the leadership process, which are: (1) the theory describes and validates those special relationships between the leader and member may result in classification of in-group and out-group (Dansereau et al., 1975), (2) model is based on the dyadic relationship between leader and follower, which is unique compared to other leadership approaches, (3) the level of exchanges (low/high) between leader and member are an important part of the communication process that establishes respect, mutual trust, and 
obligations (Graen \& Uhl-Bien, 1995), (4) based on substantial research on LMX Theory, Graen \& Uhl-Bien (1995) showed an increase in followers efforts, organizational effectiveness, performance, empowerment, and job satisfaction.

The LMX Theory also has weaknesses, which are the classification of members based on in-groups and out-groups may create inequities between groups (Scandura, 1999), model lacks an understanding of the dyadic process (leader-member exchange) associated with LMX theory (Schriesheim et al., 2001), a better understanding on whether LMX is one-dimensional or multi-dimensional (Graen \& Uhl-Bien, 1995), and the measurement scales have been developed on an ad-hoc without any presentation of clear logic or theory to justify changes in scale validity (Schriesheim et al., 1999).

\section{Compare and Contrast the Leadership Theories}

\subsection{Comparisons and Contrasts}

Situational Leadership (SLI) is focused on the leader utilizing a directive (task) and supportive (relationship) behavior in conjunction with four styles (directing, coaching, supporting, and delegating). Depending on the situation, the leader will adapt their style based on the development level and meet the changing demands of their employees (Blanchard, 2008).

Path-Goal Theory is focused on a leader choosing a behavior (directive, supportive, participative, and achievement oriented) based on employee characteristics (needs) and task characteristics (work setting) to help employees along the goal path to reach goal accomplishment (Northouse, 2007).

Leader-Member (LMX) Theory is focused on the dyadic relationship between a leader and follower based on the level of exchanges (interactions). Based on LMX, the leader will develop effective leadership by developing high-quality exchanges with all employees throughout the organization. Through the LMX leadership process, the goal is to have relationships develop from a stranger phase to mature phase in which loyalty and support is extremely high between leader and follower (Graen \& Uhl-Bien, 1991).

Each theory of leadership is specific in how leader's influence or motivate employees to achieve goal accomplishment, while Situational Leadership is focused on situations, Path-Goal is focused on Leader's behavior to compliment employees needs in a specific work environment, and LMX Leadership is focused on the exchanges (low/high) between leader and employee to establish a mature relationship.

\subsection{Similarities}

Situational Leadership, Path-Goal Leadership, and LMX Leadership are all focused on influencing and motivating the employees in an organizational environment. Based on these theories, they can work in all levels of the organization and all types of tasks or projects. Whether a leader is adapting a style, behavior, or the level of interactions (exchanges), the leader's goal is to help employees accomplish tasks and goal attainment. In the process of leadership, a leader will have to be flexible on the style or behavior that may be needed in matching employee's characteristics, tasks difficulty, and the work environment setting. As leader's better understand these factors with these leadership theories, organizations can benefit from employees feeling motivated to complete tasks (goals), which are: (1) increased job satisfaction, (2) less turnover, (3) improved attitude, (4) increased performance and efficiency, (5) cohesiveness among work units, and (6) trust, and (7) respect between leaders and employees (Graen \& Uhl-Bien, 1991; House \& Mitchell, 1974; Northouse, 2007).

\section{Impact on Future Leadership Models}

Transformational Leadership is one of the current approaches to leadership and considered a "New Leadership" paradigm in today's business environment, because it inspires, energizes, and intellectually stimulates employees during times of uncertainty (Bass, 1990; Northouse, 2007).

In today's turbulent business environment, companies are seeking leaders who possess intuitive instincts and potent abilities that enable them to reposition their organizations based on anticipated market change (Savage \& Sales, 2008). In fact, change is the "new norm" and leaders that are able to gain and maintain a competitive advantage for their company requires the ability to adapt and respond with speed and agility (Dittmar et al., 2007). According to Dittmar et al. (2007), they state that "most companies fail to achieve successful, sustained change 70 percent of the time compared to leaders that attend to the relationship between trust and engagement, they increase the success of their change initiative and secure competitive advantage" (p. 80). Unfortunately, only 25 percent of companies with employees are fully engaged, resulting in disengaged employee's that impact productivity, financial results, and failed efforts to change (Dittmar et al., 2007). 
Based on statistics in a recent Gallup poll, Dittmar et al. (2007), state that "exceptional companies with engaged workers experience a 50 percent higher employee and customer retention, 38 percent greater productivity, and 27 percent higher profits (p. 8).

How are companies going to build relationships based on trust and engagement? Many companies are focusing on transformational leaders to inspire and empower employees in today's business environment of uncertainty. As these leaders influence employees, they play a pivotal role in precipitating change, while motivating employees to improve and develop to their fullest potential (Northouse, 2007). Key factors that distinguish transformational leaders are: (1) strong role models with very high standards of moral and ethical values, (2) charismatic in providing a vision and sense of mission, (3) communicate high expectations by inspiring and motivating them to be committed to the vision, (4) stimulate innovation and creativity to challenge employees beliefs, and (5) provide a support climate for employees by acting as a coach or advisor in helping them become fully actualized (Northouse, 2007).

Based on the above factors, transformational leaders establish trust through an emotional relationship with employees that engage them to be fully committed to the company's success, they are passionate about what they are doing, and are fully integrated in supporting the company's mission and values during uncertain times. As leaders move forward in establishing creditability, they overcome the challenge of building trust between individuals, groups, and the organization through a process of creating and maintaining an engaging culture (Dittmar, 2007).

In summary, based on a quote by Warren Bennis (as cited in Dittmar et al., 2007), he says "Trust is the emotional glue that binds leaders and followers together" (p. 8). As leaders establish trust, they establish credibility, which empowers and engages employees to be creative, take risks, and collaborate within organization (Dittmar, 2007).

\section{Summary}

Three theories of leadership, Situational, Path-Goal, and Leader-Member (LMX) have been researched, analyzed, and discussed. The leaders in each theory are effective in utilizing different methods for influencing and motivating employees in completion of tasks or goal attainment. The common factor that is similar between all theories is the ability to utilize in all levels of the organization and all types of tasks or projects. Based on the research conducted in Situational, Path-Goal, and LMX Theory, they have complemented the progression of transformational leadership in today's uncertain environment of continual change.

Transformational leadership can increase performance, employee job satisfaction, and corporate reputation by permeating transformational leadership from top to bottom, communicating these philosophies to internal customers (personnel), external customers (financial backers, suppliers, clients, and the community), instill confidence in personnel and pull together for the good of the organization, and place a high value and flexibility on intellectual property (resources), and develop their people (Bass, 1990).

\section{References}

Bass, B. (1990). From Transactional to Transformational Leadership: Learning to Share the Vision. Organizational Dynamics, 18(3), 19-31. https://doi.org/10.1016/0090-2616(90)90061-S

Bennis, W. (1982). The artform of leadership. Training and Development Journal, 44-46.

Blanchard, K. (2004). Leadership and the bottom line. Executive Excellence, 21(9), 18.

Blanchard, K. (2008). Situational leadership. Leadership Excellence, 25(5), 19.

Blanchard, K.H., Zigarmi, D., \& Nelson, R.B. (1993). Situational leadership after 25 years: a retrospective. The Journal of Leadership Studies, 1(1), 22. https://doi.org/10.1177/107179199300100104

Boatwright, K.J., \& Vecchio, R.P. (2002, August). Preferences for idealized styles of supervision. The Leadership Quarterly, 13(4), 327-342. https://doi.org/10.1016/S1048-9843(02)00118-2

Dansereau, F. G., Graen, G., \& Haga, W. J. (1975). A Vertical Dyad Linkage Approach to Leadership within Formal Organizations: A Longitudinal Investigation of the Role Making Process. Organizational Behavior and Human Performance, 13, 46-78. https://doi.org/10.1016/0030-5073(75)90005-7

Dittmar, J. K., Jennings, K. R., \& Stahl-West, J. (2007). Trust and engagement. Leadership Excellence, 24(11), 8-9.

Evans, M. G. (1970). The effects of supervisory behavior on the path-goal relationship. Organizational Behavior and Human Performance, 5, 277-298. https://doi.org/10.1016/0030-5073(70)90021-8

Graeff, C. (1983, April). The Situational Leadership Theory: A Critical View. Academy of Management Review, 8(2), 285-291. https://doi.org/10.2307/257756 
Graeff, C. L. (1997). Evolution of situational leadership theory: A critical review. The Leadership Quarterly, 8(2), 153-170. https://doi.org/10.1016/S1048-9843(97)90014-X

Hersey, P., \& Blanchard, K. (1996, January). Great ideas revisited: Life-cycle theory of leadership. Training \& Development, 50(1), 42.

Hersey, P., Blanchard, K. H., \& Natemeyer, W. E. (1979). Situational Leadership, Perception, and the Impact of Power. Group \& Organization Studies (pre-1986), 4(4), 418. https://doi.org/10.1177/105960117900400404

House, R. (1971). A path-goal theory of leader effectiveness. Administrative Science Leadership Review, 16, 321-339. https://doi.org/10.2307/2391905

House, R. (1996). Path-goal theory of leadership: Lessons, legacy, and a reformulated theory. Leadership Quarterly, 7(3), 324-352. https://doi.org/10.1016/S1048-9843(96)90024-7

House, R., \& Mitchell, R. (1974). Path-goal leadership. Journal of Contemporary Business, 3, 81-97.

Jermier, J. M. (1996). The path-goal theory of leadership: A subtextual analysis. The Leadership Quarterly, 7(3), Autumn, 311-316. https://doi.org/10.1016/S1048-9843(96)90022-3

Northouse, P. G. (2007). Leadership: Theory and Practice ( $4^{\text {th }}$ ed.). Thousand Oaks, CA: Sage Publications, Inc.

Northouse, P. G. (2017). Leadership: Theory and Practice ( $7^{\text {th }}$ ed.). Thousand Oaks, CA: Sage Publications, Inc.

Reddin, W. (1967, April). The 3-D Management Style Theory. Training \& Development Journal, 21(4), 8.

Savage, A., \& Sales, M. (2008, November). The anticipatory leader: futurist, strategist and integrator. Strategy \& Leadership, 36(6), 28-35. https://doi.org/10.1108/10878570810918331

Schriesheim, C. A., Castro, S. L., \& Cogliser, C. C. (1999). Leader-Member exchange (LMX) research: A comprehensive review of theory, measurement, and data-analytic practices. Leadership Quarterly, 10, 63-113. https://doi.org/10.1016/S1048-9843(99)80009-5

Schriesheim, C. A., Castro, S. L., Zhou, X., \& Tannarubi, F. J. (2001). The folly of theorizing "A" but testing "B”: A selective level-of-analysis review of the field and a detailed leader-member exchange illustration. Leadership Quarterly, 12, 515-551. https://doi.org/10.1016/S1048-9843(01)00095-9

Schriesheim, J., \& Schriesheim, C. (1980). A Test of the Path-Goad Theory of Leadership and Some Suggested Directions for Future Research. Personnel Psychology, 33(2), 349-370. https://doi.org/10.1111/j.1744-6570.1980.tb02356.x 